\title{
Indirect assessment of pulsatile gonadotropin-releasing hormone release in agonadal prepubertal rhesus monkeys (Macaca mulatta)
}

\author{
K J Suter, C R Pohl ${ }^{1}$ and T M Plant \\ Department of Cell Biology and Physiology, University of Pittsburgh School of Medicine, Pittsburgh, Pennsylvania, USA \\ ${ }^{1}$ School of Health Sciences, Duquesne University, Pittsburgh, Pennsylvania, USA \\ (Requests for offprints should be addressed to T M Plant, Department of Cell Biology and Physiology, University of Pittsburgh School of Medicine, Pittsburgh, \\ Pennsylvania 15261, USA)
}

\begin{abstract}
The major purpose of this study was to characterize the open-loop frequency of pulsatile $\mathrm{GnRH}$ release in the female rhesus monkey at an age (15-20 months) when the prepubertal restraint on the hypothalamic-pituitary axis is maximally imposed. Additionally, evidence for pulsatile $\mathrm{GnRH}$ release in agonadal males of comparable age was also sought. Episodic LH secretion from the pituitary was used as an indirect index of $\mathrm{GnRH}$ discharges. In order to maximize the sensitivity of this in situ bioassay, the responsiveness of the pituitary gonadotrophs was usually first heightened by an i.v. intermittent infusion of the synthetic peptide. Monkeys (five females, three males) were castrated between 9 and 14 months of age, implanted with indwelling venous catheters, fitted with nylon jackets and housed in specialized cages that permitted remote access to the venous circulation with minimal restraint and without interruption of the light-darkness cycle. In
\end{abstract}

females, LH secretion was generally assessed at 20-day intervals during alternate nighttime (1900-0200 h) and daytime (0700-1400 h) windows. In males, LH was assessed less frequently and only at night. The mean frequency of pulsatile LH release in agonadal prepubertal females was 4 pulses $/ 7 \mathrm{~h}$ during the night and 2 pulses $/ 7 \mathrm{~h}$ during the day. These findings indicate that, prior to puberty in the female monkey, the GnRH pulse generator operates at a relatively slow frequency and is subjected to diurnal modulation. In males, evidence for robust pulsatile GnRH release was not observed. The striking difference in activity of the GnRH pulse generator in agonadal prepubertal male and female monkeys reinforces the view that the ontogeny of the hypothalamic drive to the pituitary-gonadal axis in higher primates, including man, is sexually differentiated.

Journal of Endocrinology (1999) 160, 35-41

\section{Introduction}

In primates, including man, the developmental profile of gonadotropin secretion from birth to adulthood is characterized by periods of elevated release neonatally and postpubertally that are separated by a prolonged phase of diminished secretion during juvenile development (see Plant 1994). The findings that, in the rhesus monkey, pulsatile gonadotropin-releasing hormone $(\mathrm{GnRH})$ release from the hypothalamus during juvenile development is considerably lower than that pubertally (Watanabe \& Terasawa 1989), and imposition of an exogenous intermittent infusion of this peptide in the juvenile elicits a pattern of luteinizing hormone (LH) and folliclestimulating hormone (FSH) release comparable to that observed in the adult (Wildt et al. 1980, Abeyawardene et al. 1989), establish that the prepubertal hiatus in gonadotropin secretion in primates is occasioned by a corresponding decline in episodic GnRH release by the hypothalamus.
Interestingly, the degree to which pulsatile $\mathrm{GnRH}$ release is suppressed during prepubertal development in primates appears to be sexually differentiated (see Plant 1994), a difference that is most notable following gonadectomy. For example, in the gonad-intact prepubertal female and male rhesus monkey, circulating LH and FSH levels are very low or not detected by RIA and therefore indistinguishable (Dierschke et al. 1974, Terasawa et al. 1984, Plant 1985, Pohl et al. 1995). At a comparable age in the agonadal state, however, the female exhibits elevated plasma FSH concentrations and distinct increments in nocturnal LH secretion (Winter et al. 1987, Pohl et al. 1995), while in the male, gonadotropin levels remain not detected (Plant 1985).

The present study was performed to further characterize sex differences in the hypothalamic mechanism that controls the onset of sexual maturation in primates. This was achieved indirectly by tracking, in agonadal male and female monkeys, hypothalamic discharges of GnRH using, as a bioassay, the LH response of the pituitary, sensitized to 
GnRH with an exogenous infusion of the decapeptide (Suter et al. 1998). Because the monkey provides an excellent paradigm for the study of the neuroendocrine control of human puberty, findings from macaques may have direct relevance to our understanding of disorders of sexual development in man. (Preliminary reports of this work were presented at the 4th International Conference on the Control of the Onset of Puberty, Pittsburgh, PA, USA in 1994 (Abstract \#2) and the 77th Annual Meeting of the Endocrine Society, Washington DC, USA in 1995 (Abstract \#OR22-1) and have appeared in the published proceedings of the first of these meetings (Perera et al. 1995).)

\section{Materials and Methods}

\section{Animals}

Five female and three male rhesus monkeys (Macaca mulatta), which were born at the Primate Research Laboratory and which had been castrated at 9-14 months of age, were used. The three males (Nos 2288, 2289 and 2456) were also employed in studies described elsewhere (Suter et al. 1998). All animals were maintained in accordance with the National Institutes of Health (NIH) Guide for the Care and Use of Laboratory Animals under a controlled photoperiod (lights on 0700-1900 h).

Gonadectomy, implantation of an indwelling venous catheter approximately 4 weeks later, subsequent maintenance of animals in remote sampling cages and blood collection were performed exactly as described previously (Suter et al. 1998). Similarly, the details for indirectly assessing endogenous pulsatile GnRH discharges using the sensitized pituitary, which was primed with an intermittent i.v. infusion of synthetic GnRH to enhance and maintain responsiveness to this decapeptide, have been fully described (Suter et al. 1998). In brief, endogenous LH discharges were identified after the priming GnRH infusion was temporarily withdrawn for 4 days. On the 4 th day of interrupted GnRH priming, sequential blood samples were collected at either 12-min (males) or 15-min (females) intervals for $7 \mathrm{~h}$ for measurement of circulating LH concentrations. Pituitary responsiveness was confirmed at the end of each nocturnal assessment window by examining the $\mathrm{LH}$ response to an i.v. bolus injection of $300 \mathrm{ng} \mathrm{GnRH}$. Following the initial assessment of LH release, cycles of intermittent exogenous GnRH administration, consisting of 6 days of $\mathrm{GnRH}$ followed by 4 days without the peptide, were imposed. Endogenous LH release was also examined in animals without prior exposure of the pituitary to exogenous GnRH.

\section{Experimental protocol}

Endogenous pulsatile LH release was characterized between 15 and 20 months of age, a period which falls within the phase of development during which the prepubertal restraint on GnRH release is imposed (Terasawa et al. 1984, Plant 1985, Pohl et al. 1995). Because LH release, and presumably that of $\mathrm{GnRH}$, has been shown to be diurnally modulated with enhanced nocturnal secretion (Plant 1985, Pohl et al. 1995), most assessments were performed at night (1900-0200 h). In females, attempts were generally made to assess LH secretion every 20 days, alternating between daytime (0700-1400 h) and nighttime windows. Assessment of LH release in males was conducted every 40 days, and only during the night. These schedules were interrupted occasionally when patency in the catheters was lost. In addition, data from incomplete assessments were excluded from analysis.

Experiment 1 Pulsatile LH release was assessed in three agonadal juvenile female monkeys with pituitaries in which the responsiveness to $\mathrm{GnRH}$ had been enhanced by exogenous GnRH priming. Nocturnal assessments of endogenous LH release were performed on each of these animals at three different ages: 15-16 months (five assessments), 17-18 months (five assessments) and 1920 months (four assessments). Daytime assessments at these ages numbered five, four and five respectively.

Experiment 2 In order to examine the possibility that, in Experiment 1, the pattern of endogenous LH release was influenced by the i.v. infusion of synthetic GnRH, administered to heighten responsiveness of the gonadotrophs, two additional animals were studied. These monkeys did not receive exogenous $\mathrm{GnRH}$ priming. Nocturnal assessments were performed in these animals at 15-16 months of age (three assessments), 17-18 months (two assessments) and 19-20 months (one assessment). Daytime assessments at these ages numbered three, two and two respectively.

Experiment 3 Pulsatile LH release was assessed in three agonadal juvenile male monkeys with pituitaries which had been primed with the intermittent regimen of GnRH. Nocturnal assessments were performed in these animals at 15-16 (five assessments), 17-18 (five assessments) and 19-20 (three assessments) months of age. These animals were also employed for studies described previously (Suter et al. 1998). In that study, only data obtained between 14 and 16 months of age (the age at which LH was first assessed) and after 22 months of age were analyzed.

\section{LH assay}

Plasma was harvested and frozen until LH was measured using a cynomolgus LH-anti-human chorionic gonadotropin (R13, Pool D) RIA system with rhesus pituitary preparation WP-XV-20 (NIH rh-LH-RP-1) as standard (Peckham \& Tontala 1981). The minimum detectable 
concentration ranged from $10 \cdot 0$ to $14 \cdot 2 \mathrm{ng} / \mathrm{ml}$. Inter- and intraassay coefficients of variation were 6.8 and $7 \cdot 3 \%$ respectively.

\section{LH pulse analysis and statistics}

A discharge of GnRH was inferred whenever an increment in circulating LH concentration in 7-h windows of sequential blood collection was identified as an LH pulse by the pulse detection algorithm, Pulsar (Merriam \& Wachter 1982), using the same $G$ values described previously (Suter et al. 1998). This program was used to determine the number of pulses per 7-h sampling period (frequency), the average amplitude of LH pulses, and the average plasma LH concentration for individual 7-h windows. For each of the three ages studied, a mean value of each of the foregoing parameters was obtained for every monkey. These means were then averaged to produce group means for each age. Windows in which LH pulses were not detected were excluded from the determination of average amplitudes. For purposes of calculations, the assay limit of detection was substituted for not-detected sample values. LH pulse parameters for daytime and nighttime windows were compared by two-factor ANOVA with repeated measures (age, time of day) and by Mann-Whitney U-tests. A value of $P<0 \cdot 05$ was accepted for statistical significance.

\section{Results}

\section{Experiment 1}

Representative profiles of pulsatile LH release from the sensitized pituitary, in ovariectomized prepubertal rhesus monkeys, are shown in Fig. 1. Discharges of LH were invariably observed at night, and during the day in many cases. In two of the three monkeys, this pulsatile pattern of secretion was robust. Mean LH pulse frequency during the daytime and nighttime was approximately 2 and 4 pulses/ $7 \mathrm{~h}$ respectively, and the diurnal effect was significant at 15-16 months and 19-20 months (Fig. 2). There was no evidence for a developmental change $(P>0.05)$ in $\mathrm{LH}$ pulse frequency during the study period, 15-20 months of age (Fig. 2). Mean plasma LH concentrations, which frequently exceeded $200 \mathrm{ng} / \mathrm{ml}$ during the night, and mean LH pulse amplitudes for the three age groups are shown in Fig. 2.

\section{Experiment 2}

In the two ovariectomized prepubertal animals, in which the unprimed pituitary was used to assess pulsatile $\mathrm{LH}$ release, the frequency of secretion and its diurnal modulation (Fig. 3) were similar to those observed in Experiment 1 employing the sensitized pituitary. A comparison
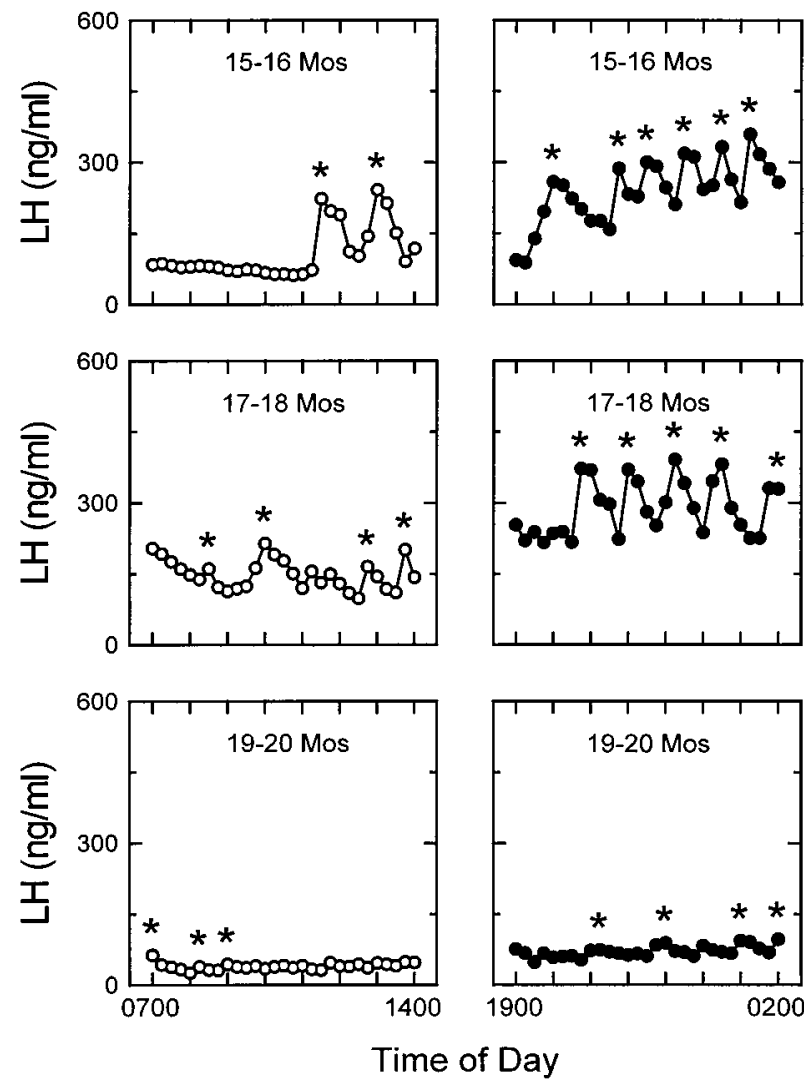

Figure 1 Daytime and nighttime patterns of moment to moment changes in $\mathrm{LH}$ secretion (the index employed to indirectly assess pulsatile $\mathrm{GnRH}$ release) from the pituitary, between 0700 and $1400 \mathrm{~h}(\bigcirc$, left hand panels) and 1900 and $0200 \mathrm{~h}(\bullet$, right hand panels), in three agonadal female monkeys during successive 2-month periods between the ages of 15 and 20 months. Note, the results shown for each age were obtained from a different female, therefore the relatively low $\mathrm{LH}$ level for the female at 19-20 months of age does not represent a developmental trend (see Fig. 2). Asterisks indicate increments in circulating LH concentrations identified as episodes of secretion by Pulsar and therefore reflecting discharges of hypothalamic $\mathrm{GnRH}$ release. The responsiveness of the pituitaries to $\mathrm{GnRH}$ in these animals was heightened by intermittent stimulation with the synthetic peptide prior to the assessment of endogenous $\mathrm{GnRH}$ release.

of $\mathrm{LH}$ pulse frequency in the two paradigms is shown in Table 1. Mean circulating LH levels in these animals were less than those observed in monkeys with a sensitized pituitary, although this difference was statistically significant only during the daytime. In the unprimed animals, mean daytime and nocturnal LH levels for the ages studied ranged from 10 to $60 \mathrm{ng} / \mathrm{ml}$ (average $27 \pm 7 \cdot 6$ ) and from 10 to $90 \mathrm{ng} / \mathrm{ml}$ (average $42 \cdot 8 \pm 16 \cdot 5$ ) respectively.

\section{Experiment 3}

In contrast to agonadal prepubertal females, nocturnal pulsatile LH release in three castrated males of comparable 

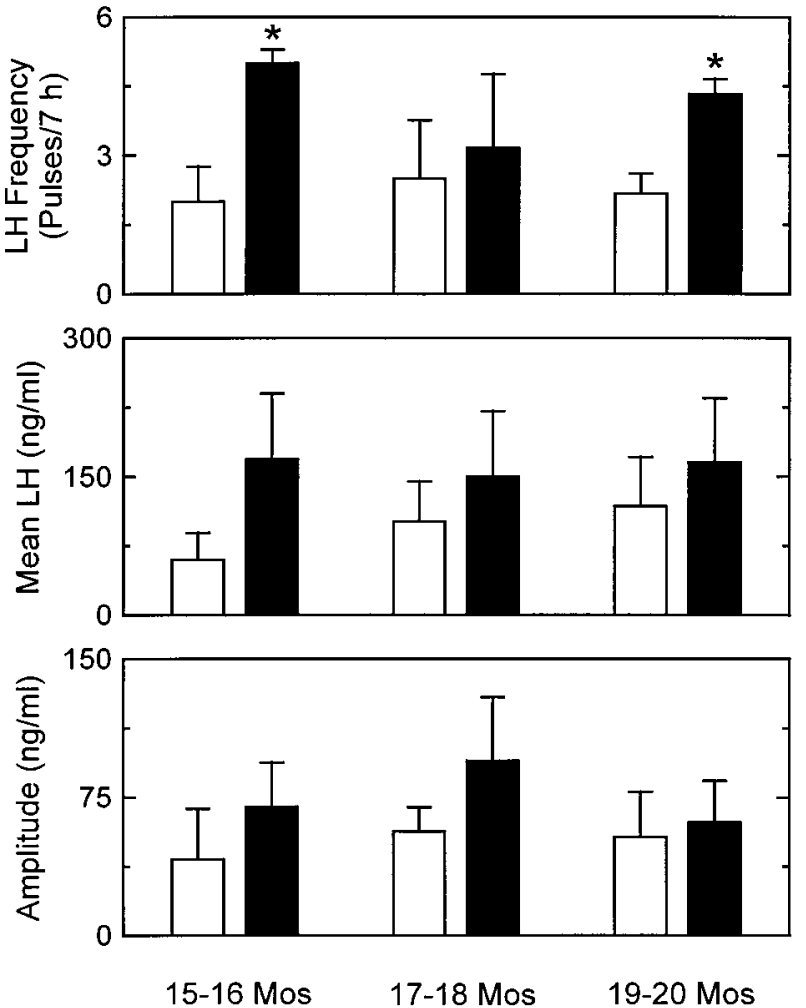

Figure 2 LH response of the pituitary, in which responsiveness to $\mathrm{GnRH}$ was heightened by intermittent stimulation with synthetic peptide, to endogenous GnRH release from the hypothalamus of agonadal female rhesus monkeys $(n=3)$ during successive 2-month periods between the ages of 15 and 20 months. The top panel shows mean LH pulse frequencies (the index of $\mathrm{GnRH}$ pulse frequency) during the daytime (0700-1400 h, open bars) and nighttime (1900-0200 $\mathrm{h}$, closed bars) and the middle and bottom panels show corresponding values for mean concentrations of circulating LH and mean LH pulse amplitude respectively. Vertical lines with small horizontal bars show S.E.M. Asterisks indicate significant differences between daytime and nighttime windows.

age was observed only on occasion, and in those instances where an LH discharge was identified the resulting pulse amplitude was small (mean $=11 \mathrm{ng} / \mathrm{ml}$ ). The mean LH pulse frequencies for the three ages examined were $0 \cdot 7 \pm 0 \cdot 3$ pulses $/ 7 \mathrm{~h} \quad(15-16$ months; $n=3), \quad 0 \cdot 5 \pm 0 \cdot 3$ pulses $/ 7 \mathrm{~h}(17-18$ months; $n=3)$ and $0 \cdot 3 \pm 0 \cdot 3$ pulses $/ 7 \mathrm{~h}$ (19-20 months; $n=2)$. The absence of robust episodes of LH secretion in males was not due to a failure to sensitize the gonadotroph, since the standard exogenous GnRH challenge that was administered following each assessment of endogenous peptide secretion consistently induced LH release. The mean increments in circulating LH concentrations elicited by the $\mathrm{GnRH}$ challenge were $92 \pm 6 \mathrm{ng} /$ $\mathrm{ml}(n=3), 61 \pm 26 \mathrm{ng} / \mathrm{ml}(n=3)$ and $77 \pm 13 \mathrm{ng} / \mathrm{ml}(n=2)$ at the respective ages studied. Nocturnal LH pulse frequency, LH pulse amplitude and mean LH concentrations in the male and in the female were markedly different
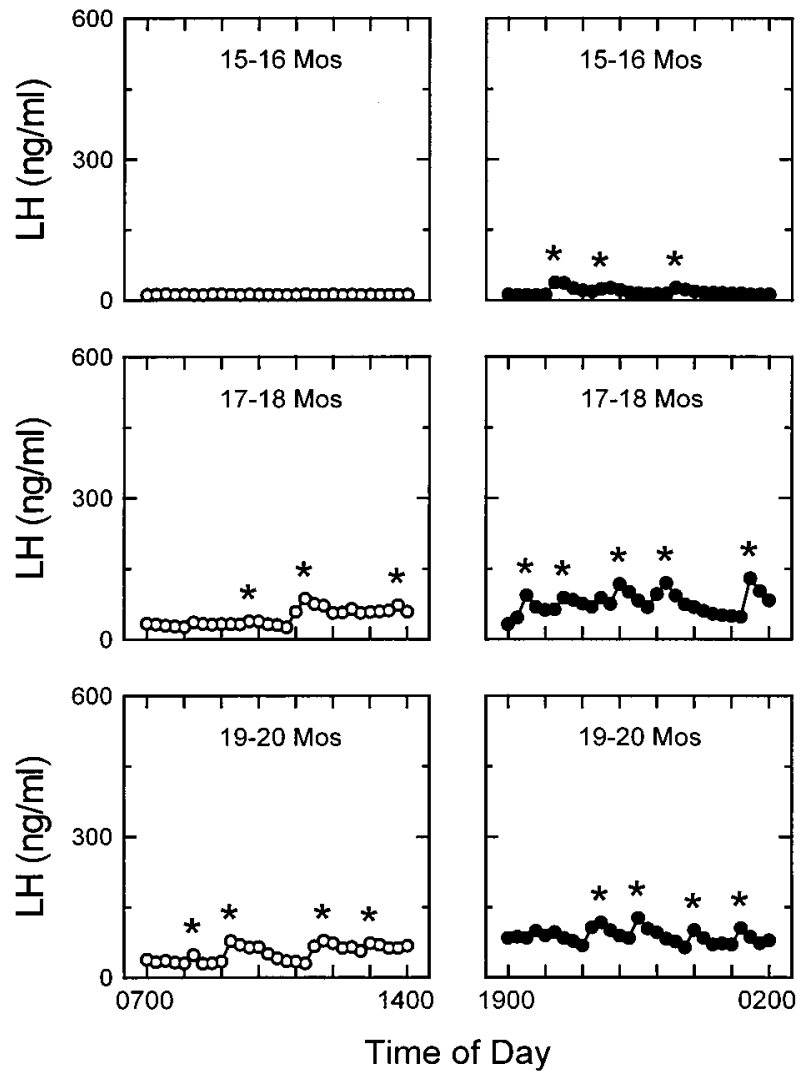

Figure 3 Daytime and nighttime patterns of pulsatile GnRH release, as reflected by episodic $\mathrm{LH}$ secretion from the unprimed pituitary between 0700 and $1400 \mathrm{~h}(\mathrm{O}$, left hand panels) and 1900 to $0200 \mathrm{~h}$ ( , right hand panels) respectively, in two agonadal female monkeys at 15-20 months of age. The results shown for 17-18 and 19-20 months were obtained from the same female. Asterisks indicate increments in circulating LH concentrations identified as secretory episodes by Pulsar and therefore reflecting discharges of hypothalamic $\mathrm{GnRH}$ release.

(Fig. 4). When data for the three age groups were combined, the difference between males and females for each of the three parameters was significant $(P<0 \cdot 005)$.

Table 1 Frequencies of pulsatile GnRH release in agonadal prepubertal female monkeys with and without prior sensitization to GnRH. Values are mean \pm S.E.M. ( $n$ ) for all ages combined

Pulses/7 h

Sensitized

1900-0200 h

0700-1400 h

Unsensitized

1900-0200 h

0700-1400 h

$$
\begin{aligned}
& 4 \cdot 2 \pm 0 \cdot 6(9)^{*} \\
& 2 \cdot 2 \pm 0 \cdot 4(9) \\
& 3 \cdot 2 \pm 0 \cdot 7(5) \\
& 1 \cdot 6 \pm 0 \cdot 7(6)
\end{aligned}
$$

There were no significant differences between sensitized and unsensitized. ${ }^{*} P<0 \cdot 01$ vs $0700-1400 \mathrm{~h}$ value. 

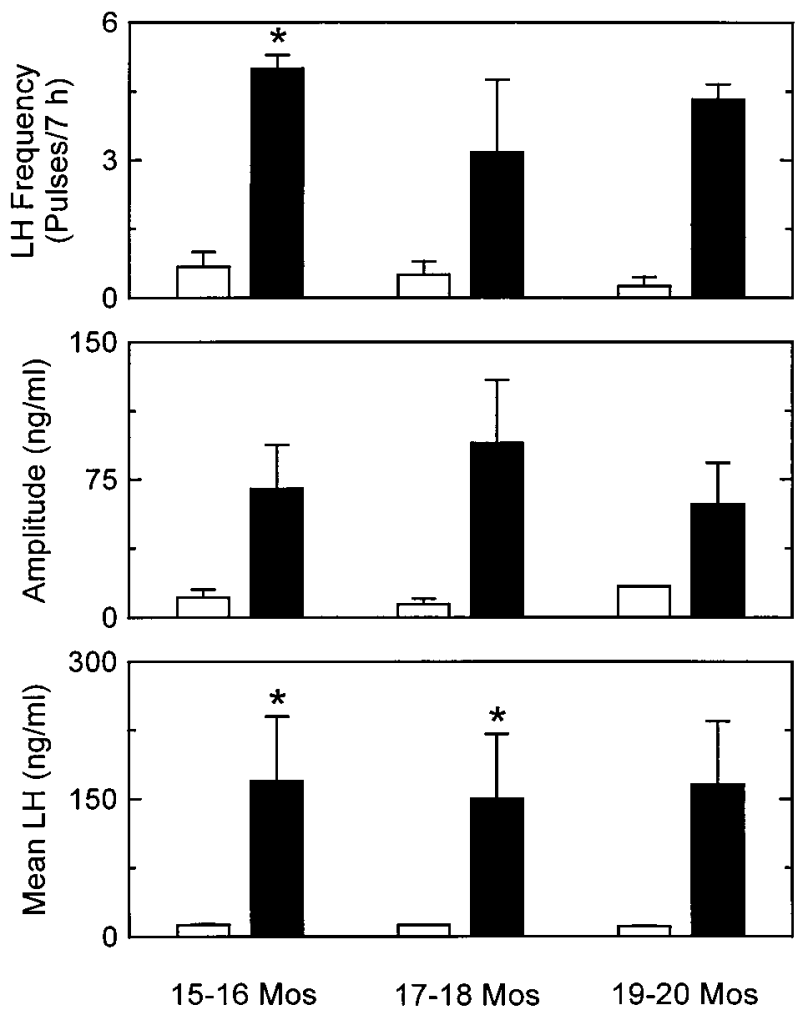

Figure 4 Sex differences in nocturnal (1900-0200 h) LH responses of the primed pituitary to endogenous $\mathrm{GnRH}$ release from the hypothalamus of agonadal male (open bars) and female (closed bars) monkeys during successive 2 -month periods between the ages of 15 and 20 months. The top panel shows mean LH pulse frequency (the index of GnRH pulse frequency) and the middle and bottom panels show corresponding values for mean $\mathrm{LH}$ pulse amplitude and mean concentrations of circulating $\mathrm{LH}$ respectively; $n=3$ for each group except for the 19- to 20-month-old males where $n=2$. Vertical lines with small horizontal bars show S.E.M. The data for the females are reproduced for the purpose of comparison from Fig. 2. Asterisks indicate significant difference between male and female.

\section{Discussion}

Although the prepubertal phase of development in both female and male rhesus monkeys is characterized by a diminution in the hypophysiotropic drive to the gonadotroph (see Plant 1994), the recent finding of nocturnal elevations in LH secretion in agonadal female rhesus monkeys at this age (Pohl et al. 1995) suggests that, in this gender, the hypothalamic mechanism underlying the pulsatile discharge of $\mathrm{GnRH}$ is only partially inactivated during the prepubertal phase of development. This notion was strongly reinforced by the present study. Use of the sensitized pituitary as a bioassay for endogenous $\mathrm{GnRH}$ release revealed that open-loop pulsatile GnRH release in the prepubertal female occurs during the light and darkness phases of the 24-h cycle. The frequency of $\mathrm{LH}$ discharges, and therefore presumably of those of $\mathrm{GnRH}$, during the day and night was approximately 2 and 4 pulses $/ 7 \mathrm{~h}$ respectively. This indirect assessment of the frequency of pulsatile $\mathrm{GnRH}$ release in the agonadal prepubertal female monkey is at variance with the results of studies that have employed hypothalamic perfusion to monitor directly discharges of the peptide. In such studies, inter-GnRH-pulse intervals of approximately $1 \mathrm{~h}$ have been described for juvenile ovariectomized monkeys (Chongthammakun \& Terasawa 1993, Chongthammakun et al. 1993). In adult ovariectomized monkeys, direct and indirect assessment of $\mathrm{GnRH}$ pulse frequency has yielded comparable estimates of this parameter, namely approximately 1 pulse/h (Dierschke et al. 1970, Wilson et al. 1984, Gearing \& Terasawa 1991). Since the present indirect analysis of $\mathrm{GnRH}$ pulse frequency in the prepubertal animal employed a pituitary with a responsiveness similar to that in the adult, the lack of congruency between the results obtained by the two methods in the prepubertal state must therefore be related to the smaller GnRH signal at this stage of development.

In the present study, the magnitude of pituitary LH release elicited in response to the hypophysiotropic drive from the hypothalamus of the agonadal prepubertal female was surprisingly large. In the adult ovariectomized monkey, the circhoral release of GnRH results in mean levels of circulating LH ranging in general from 100 to $200 \mathrm{ng} / \mathrm{ml}$ (Dierschke et al. 1970), concentrations which were frequently observed in the present study in response to the nocturnal release of pulsatile $\mathrm{GnRH}$ from the hypothalamus of the 15- to 20-month-old female. While the relationship between frequency and amplitude modulation of a pulsatile pattern of $\mathrm{GnRH}$ stimulation, on the one hand, and its strength as a drive to the gonadotroph, on the other, is complex, similar levels of mean LH are intuitively equated to comparable GnRH drives. Thus, we were concerned that the pulsatile i.v. GnRH infusion, which was employed in the present study to enhance the response of the gonadotroph to endogenous GnRH, may have also influenced the activity of the $\mathrm{GnRH}$ pulse generator of the prepubertal hypothalamus. However, the frequency of pulsatile LH $(\mathrm{GnRH})$ release in agonadal females, which did not receive a priming infusion of the synthetic peptide, was similar to that observed in animals with a sensitized pituitary. The latter result suggests that the frequency of the GnRH pulse generator in the hypothalamus of the prepubertal monkey was not modulated by the exogenous infusion; this view is consistent with the finding that, in the adult monkey, electrophysiological correlates of $\mathrm{GnRH}$ pulse generator activity are not influenced by treatment with $\mathrm{GnRH}$ receptor ligands (Ördög et al. 1997).

Previous studies employing pituitary LH secretion as an index of the frequency of pulsatile GnRH release indicate that the neural timing mechanism governing this mode of release also operates at a relatively slow open-loop frequency (1 pulse/4h) during neonatal development 
(Plant 1986). Thus, an open-loop GnRH pulse frequency well below that of the circhoral pattern of $\mathrm{GnRH}$ release in the adult (Hotchkiss \& Knobil 1994) may be a hallmark of the prepubertal phase of female development in this species. If this line of reasoning is accepted, it must be concluded that the re-augmentation of the hypophysiotropic drive that occurs at approximately 24 months of age in ovariectomized monkeys, and which is presumably the cardinal event underlying the initiation of female puberty in this species and in man, must involve, in part, an acceleration in the frequency of the GnRH pulse generator. In agonadal girls of prepubertal age $(2-10$ years) with Turner's syndrome, robust pulsatile $\mathrm{GnRH}$ release, as reflected by circulating $\mathrm{LH}$ concentrations, has been observed with mean frequencies ranging between 2 and 6 pulses/12 h (Levine Ross et al. 1983, Mauras et al. 1989, Hosoda et al. 1991). Moreover, in two of the foregoing studies (Levine Ross et al. 1983, Hosoda et al. 1991), there was a suggestion that LH pulse frequency in girls older than 10 years was greater than that in the younger girls.

The earlier observation in this laboratory that, in agonadal female monkeys aged 10-20 months, circulating LH concentrations at night are greater than those during the day (Pohl et al. 1995), indicates that the open-loop hypophysiotropic drive to the gonadotroph during this phase of development is diurnally modulated. The present finding that, in ovariectomized monkeys at a similar stage of development, GnRH pulse frequency at night is twice that during the day suggests that the nocturnal elevation in the hypothalamic stimulus to LH secretion is mediated, at least in part, by an acceleration of the GnRH pulse generator at night. Whether a similar day-night difference exists in the open-loop activity of the GnRH pulse generator in the human female of prepubertal age is less clear (Levine Ross et al. 1983, Hosada et al. 1991). Interestingly, in the adult ovariectomized monkey there is either no change or a deceleration of the $\mathrm{GnRH}$ pulse generator during the night (Ji et al. 1989, O’Byrne et al. 1993).

Lastly, the failure of the sensitized pituitary to detect robust patterns of $\mathrm{GnRH}$ discharges in castrate male monkeys aged 15-20 months, a phase of development when the GnRH pulse generator is unequivocally active in the agonadal female, strongly reinforces the earlier conclusion that the ontogeny of pulsatile $\mathrm{GnRH}$ release in primates is sexually differentiated (Plant 1986, Winter et al. 1987).

\section{Acknowledgements}

This work was supported by NIH Grants HD13254 and HD08610. We are most grateful to the Contraceptive Development Branch, National Institute of Child Health and Human Development (Bethesda, MD, USA) and the National Institute of Diabetes, Digestive and Kidney
Diseases (Bethesda, MD, USA), through the National Hormone and Pituitary Program, University of Maryland School of Medicine, for the gift of GnRH and assay reagents used in this study. The authors also wish to acknowledge the expert technical assistance provided by Deborah Bolette and Deborah Berger and the staff of the Primate and Assay Cores of the Center for Research in Reproductive Physiology, University of Pittsburgh School of Medicine.

\section{References}

Abeyawardene SA, Vale WW, Marshall GR \& Plant TM 1989 Circulating inhibin $\alpha$-concentrations in infant, prepubertal and adult rhesus monkeys (Macaca mulatta) and in juvenile males during premature initiation of puberty with pulsatile gonadotropin-releasing hormone treatment. Endocrinology 125 250-256.

Chongthammakun S \& Terasawa E 1993 Negative feedback effects of estrogen on luteinizing hormone-releasing hormone release occur in pubertal, but not prepubertal, ovariectomized female rhesus monkeys. Endocrinology 132 735-743.

Chongthammakun S, Claypool LE \& Terasawa E 1993 Ovariectomy increases in vivo luteinizing hormone-releasing hormone release in pubertal, but not prepubertal, female rhesus monkeys. Journal of Neuroendocrinology $\mathbf{5} 41-50$.

Dierschke DJ, Bhattacharya AN, Atkinson LE \& Knobil E 1970 Circhoral oscillations of plasma LH levels in the ovariectomized rhesus monkey. Endocrinology 87 850-853.

Dierschke DJ, Karsch FJ, Weick RF, Weiss G, Hotchkiss J \& Knobil E 1974 Hypothalamic-pituitary regulation of puberty: feedback control of gonadotropin secretion in the rhesus monkey. In Control of the Onset of Puberty, pp 105-114. Eds MM Grumbach, GD Grave \& FE Mayer. New York: Wiley and Sons.

Gearing M \& Terasawa E 1991 The alpha-1-adrenergic neuronal system is involved in the pulsatile release of luteinizing hormonereleasing hormone in the ovariectomized female rhesus monkey. Neuroendocrinology 53 373-381.

Hosoda A, Fujieda K, Matsuura N, Okuno A \& Yuri K 1991 Agerelated change of pulsatile gonadotropin secretion in Turner syndrome. Pediatric Research 29 196-200.

Hotchkiss J \& Knobil E 1994 The menstrual cycle and its neuroendocrine control. In The Physiology of Reproduction, edn 2, pp 711-749. Eds E Knobil \& JD Neill. New York: Raven Press.

Ji W-Z, Kaynard AH, Pau K-YF, Hess DL, Baughman WL \& Spies HG 1989 Endogenous opiates regulate the nocturnal reduction in luteinizing hormone pulse frequency during the luteal phase of the macaque menstrual cycle. Biology of Reproduction 41 1024-1033.

Levine Ross J, Loriaux DL \& Cutler GB Jr 1983 Developmental changes in neuroendocrine regulation of gonadotropin secretion in gonadal dysgenesis. Journal of Clinical Endocrinology and Metabolism 57 288-293.

Mauras N, Rogol AD \& Veldhuis JD 1989 Specific, time-dependent actions of low-dose ethinyl estradiol administration on the episodic release of growth hormone, follicle-stimulating hormone, and luteinizing hormone in prepubertal girls with Turner's syndrome. Journal of Clinical Endocrinology and Metabolism 69 1053-1058.

Merriam GR \& Wachter KW 1982 Algorithms for the study of episodic hormone secretion. American Journal of Physiology 243 E310-E318.

O'Byrne KT, Thalabard J-C, Chiappini SE, Chen M-D, Hotchkiss J \& Knobil E 1993 Ambient light modifies gonadotropin-releasing hormone pulse generator frequency in the rhesus monkey. Endocrinology 133 1520-1524. 
Ördög T, Chen MD, Nishihara M, Connaughton MA, Goldsmith JR \& Knobil E 1997 On the role of gonadotropin-releasing hormone $(\mathrm{GnRH})$ in the operation of the GnRH pulse generator in the rhesus monkey. Neuroendocrinology 65 307-313.

Peckham WD \& Tontala FJ 1981 A new radioimmunoassay for monkey luteinizing hormone. Proceedings of the 11th Annual Meeting of the Society for the Study of Reproduction, Corvallis, OR, USA. Abstract 193.

Perera AD, Suter KJ, Pohl CR \& Plant TM 1995 The neurobiology of the prepubertal restraint of pulsatile $\mathrm{GnRH}$ release in the monkey. In: The Neurobiology of Puberty, pp 175-184. Eds TM Plant \& PA Lee. Bristol: Society for Endocrinology.

Plant TM 1985 A study of the role of the postnatal testes in determining the ontogeny of gonadotropin secretion in the male rhesus monkey (Macaca mulatta). Endocrinology 116 13411350.

Plant TM 1986 A striking sex difference in the gonadotropin response to gonadectomy during infantile development in the rhesus monkey (Macaca mulatta). Endocrinology 119 539-545.

Plant TM 1994 Puberty in primates. In The Physiology of Reproduction, edn 2, pp 453-485. Eds E Knobil \& JD Neill. New York: Raven Press.

Pohl CR, DeRidder CM \& Plant TM 1995 Gonadal and nongonadal mechanisms contribute to the prepubertal hiatus in gonadotropin secretion in the female rhesus monkey (Macaca mulatta). Journal of Clinical Endocrinology and Metabolism 80 2094-2101.
Suter KJ, Pohl CR \& Plant TM 1998 The pattern and tempo of the pubertal re-augmentation of open-loop pulsatile GnRH release assessed indirectly in the male rhesus monkey (Macaca mulatta). Endocrinology 139 2774-2783.

Terasawa E, Bridson WE, Nass TE, Noonan JJ \& Dierschke DJ 1984 Developmental changes in the luteinizing hormone secretory pattern in peripubertal female rhesus monkeys: comparisons between gonadally intact and ovariectomized animals. Endocrinology $1152233-2240$.

Watanabe G \& Terasawa E 1989 In vivo release of luteinizing hormone releasing hormone increases with puberty in the female rhesus monkey. Endocrinology 125 92-99.

Wildt L, Marshall G \& Knobil E 1980 Experimental induction of puberty in the infantile female rhesus monkey. Science $2071373-$ 1375.

Wilson RC, Kesner JS, Kaufman J-M, Uemura T, Akema T \& Knobil E 1984 Central electrophysiologic correlates of pulsatile luteinizing hormone secretion in the rhesus monkey. Neuroendocrinology 39 256-260.

Winter JSD, Ellsworth L, Fuller G, Hobson WC, Reyes FI \& Faiman C 1987 The role of gonadal steroids in feedback regulation of gonadotropin secretion at different stages of primate development. Acta Endocrinologica 114 257-268.

Received 5 May 1998

Accepted 24 August 1998 